\title{
PENGURANGAN DEFECT PADA PRODUK SEPATU DENGAN MENGINTEGRASIKAN STATISTICAL PROCESS CONTROL (SPC) DAN ROOT CAUSE ANALYSIS (RCA) STUDI KASUS PT. XYZ
}

\author{
Moch. Teguh Fajrin, Wiwik Sulistiyowati \\ Program Studi teknik Industri \\ Universitas Muhammadiyah Sidoarjo, Sidoarjo, Jawa Timur 61271 \\ mteguhcr7@yahoo.co.id
}

\begin{abstract}
PT. XYZ is a foreign capital investment companies are located in one area of town of Sidoarjo which has more than 7000 employees in it and of course want to have a high quality product. PT footwear products. XYZ is the world quality products that promote the quality and comfort of the wearer. Problems that occur in the production process of PT. XYZ of 7 -injection engine that has the most number of engine defect is 5.6 and 7. Quality products at heavily influence the shoe production to consumers. If damaged, then the product can not be distributed to consumers. Therefore, the quality of the shoes must be maintained for the successful marketing of the product. From our previous improvements made in reducing the defect in the production process, but the result is less than optimal, so do research that aims to make improvements again with another method. The method used in this research is to apply the methods of Statistical Processing Control (SPC) and Root Cause Analysis (RCA). The results of the check sheet analysis and Pareto diagram can be seen the frequency of product defects (defects) over roughing most occurred in March 2016 as many as 345 shoes (62\%) of the total production of 489 products. Then the second frequency in February 2016 as many as 214 shoes (38\%) of the total production of 357 products. And from the image Control Chart $P$ can be concluded that the data are in a state of uncontrolled. Because of all these 50 data, there is one data point that is outside the control limits (out of control), on the 4th point the data has a value of the proportion of 1, beyond the limits Upper Control Limit (UCL) is equal to 0.938. During the dots located within the boundaries of a controller, a process is under controlled conditions, and no action required. However, one point that lies outside the control limit is interpreted as the fact that the quality control in the production process (injection) PT. XYZ uncontrolled or still experiencing irregularities. Whereas the causes of the failure of a critical process in the production process are humans, machines, methods and materials.
\end{abstract}

Key words: Defect Production, Shoes, Quality, Statistical Process Control (SPC), Root Cause Analysis $(R C A)$

\section{PENDAHULUAN}

PT. XYZ merupakan perusahaan penanam modal asing yang terletak di salah satu wilayah kota Sidoarjo. Dan produk sepatu PT. XYZ adalah produk kualitas dunia yang mengedepankan kualitas dan kenyamanan pemakainya.

Permasalahan yang terjadi pada proses produksi PT. XYZ dari 7 mesin injection yang paling banyak memiliki jumlah defect adalah mesin 5,6 dan 7 .

Dari usaha perbaikan yang sebelumnya dilakukan dalam mengurangi defect dalam proses produksi ternyata hasilnya kurang optimal, sehingga dilakukan penelitian yang bertujuan untuk melakukan perbaikan kembali dengan metode lain. Metode yang digunakan dalam penelitian ini adalah dengan menerapkan metode Statistical Processing Control (SPC) dan Root Cause Analysis (RCA).

\section{TINJAUAN PUSTAKA}

Menurut Montgomery (1985). Sangat perlu produk memenuhi syarat-syarat dari orang yang menggunakannya. Oleh karena itu definisi kita tentang kualitas adalah kualitas yang berarti kecocokan penggunaannya.

Pengendalian kualitas merupakan aktivitas teknik dan manajemen, melalui mana kita mengukur karakteristik kualitas dari produk tersebut, kemudian membandingkan hasil pengukuran itu dengan spesifikasi produk yang diinginkan pelanggan, serta mengambil tindakan 
peningkatan yang tepat apabila ditemukan perbedaan di antara kinerja aktual dan standar (Gaspersz, 2003).

Dari beberapa pendapat tentang kualitas tersebut dapat di tarik kesimpulan, khususnya oleh suatu perusahaan, bahwa untuk meningkatkan , mempertahankan dan mencapai kualitas yang sesuai dengan standar yang diharapkan adalah dengan menerapkan atau menggunakan teknik pengendalian kualitas. Dalam perkembanganya PT. XYZ dari tahun ke tahun dalam memproduksi sepatu teknik pengendalian kualitas ini sangat perlu untuk diterapkan ke dalam berbagai proses khususnya di area produksi, karena kualitas dari suatu produk sangat diperlukan oleh suatu perusahaan sehingga nantinya dapat menarik dan mempunyai daya saing suatu produk bagi konsumen.

Menurut Lindsay (2007) Statistical Process Control (SPC) adalah metodologi untuk memonitor proses agar ditemukan sebab akibat khusus variasi dan memberi tanda jika dibutuhkan tindakan korektif.

Pengendalian kualitas secara statistik dengan menggunakan metode Statistical Process Control mempunyai 7 (tujuh) alat statistik utama yang dapat digunakan sebagai alat bantu untuk mengendalikan kualitas yang dikenal dengan istilah Seven Tools. Alat bantu Statistical Process Control (SPC) adalah sebagai berikut : (1) Lembar pemeriksaan (Check Sheet), check sheet atau lembar pemeriksaan merupakan alat pengumpul dan penganalisis data yang disajikan dalam bentuk tabel yang berisi data jumlah barang yang diproduksi dan jenis ketidaksesuaian beserta dengan jumlah yang dihasilkannya. Lembar periksa adalah suatu formulir, dimana itemitem yang akan diperiksa telah dicetak dalam formulir itu, dengan maksud agar data dapat dikumpulkan secara mudah dan ringkas (Gaspersz, 2003). (2) Diagram sebar (Scatter Diagram), scatter diagram atau disebut juga dengan peta korelasi adalah grafik yang menampilkan hubungan antara dua variabel apakah hubungan antara dua variabel tersebut kuat atau tidak, yaitu antara faktor proses yang mempengaruhi proses dengan kualitas produk. (3) Diagram sebab-akibat (Cause and Effect Diagram), diagram ini disebut juga diagram tulang ikan (fishbone chart) dan berguna untuk memperlihatkan faktor-faktor utama yang berpengaruh pada kualitas dan mempunyai akibat pada masalah yang kita pelajari. (4) Diagram pareto (Pareto Analysis), diagram pareto adalah grafik balok dan grafik baris yang menggambarkan perbandingan masing-masing jenis data terhadap keseluruhan. Dengan memakai diagram pareto, dapat terlihat masalah mana yang dominan sehingga dapat mengetahui prioritas penyelesaian masalah. Fungsi diagram pareto adalah untuk mengidentifikasi atau menyeleksi masalah utama untuk peningkatan kualitas dari yang paling besar ke yang paling kecil. (5) Diagram alir/ diagram proses (Process Flow Chart), Diagram alir secara grafis menunjukkan sebuah proses atau sistem dengan menggunakan kotak dan garis yang saling berhubungan. (6) Histogram, histogram adalah suatu alat yang membantu untuk menentukan variasi dalam proses. Berbentuk diagram batang yang menunjukkan tabulasi dari data yang diatur berdasarkan ukurannya. Tabulasi data ini umumnya dikenal dengan distribusi frekuensi. (7) Peta kendali (Control Chart), Peta kendali adalah suatu alat yang secara grafis digunakan untuk memonitor dan mengevaluasi apakah suatu aktivitas atau proses berada dalam pengendalian kualitas secara statistika atau tidak sehingga dapat memecahkan masalah dan menghasilkan perbaikan kualitas.

Root Cause Analysis (RCA) adalah suatu proses mengidentifikasi dan menentukan akar penyebab dari permasalahan tertentu dengan tujuan membangun dan mengimplementasikan solusi yang akan mencegah terjadinya pengulangan masalah (Doggett, 2005) dalam Lindawati, dkk (2013).

Root Cause Analysis (RCA) Merupakan metode yang terstruktur untuk menemukan secara pasti awal kesalahan yang menjadi akar penyebab dari kegagalan sebuah sistem atau peralatan. Tujuan utama RCA adalah meningkatkan keandalan sebuah sistem sehingga akan meningkatkan faktor ketersediaan sistem tersebut. Setiap munculnya penyebab kegagalan diinvestigasi dan dilaporkan adalah agar sedapat mungkin kita dapat mengidentifikasi langkah perbaikan guna mencegah munculnya kejadian yang sama dan lebih jauh dapat melindungi kesehatan dan keselamatan, pekerja dan lingkungan (DOE, 1992) dalam Alwi (2011). 
Terdapat berbagai metode evaluasi yang terstruktur untuk mengidentifikasi akar penyebab (Root Cause) suatu permasalahan. Lima metode populer untuk mengidentifikasi akar penyebab suatu permasalahan (Jing, 2008) dalam Zoraya (2012), yaitu: (1). Is/Is Not Comparative Analysis, merupakan metode komparatif yang digunakan untuk permasalahan sederhana, dapat memberikan gambaran detil apa yang terjadi dan telah sering digunakan untuk menginvestigasi akar masalah. (2). 5 Why Method, merupakan alat analisis sederhana yang memungkinkan untuk menginvestigasi suatu masalah secara mendalam.(3). Fishbone Diagram, merupakan alat analisis yang populer, yang sangat baik untuk menginvestigasi penyebab dalam jumlah besar.(4). Cause and effect matrix, merupakan matrik sebab akibat yang dituliskan dalam bentuk tabel dan memberikan bobot pada setiap faktor penyebab masalah.(5). Root Cause Tree, merupakan alat analisis sebab akibat yang paling sesuai untuk permasalahan yang kompleks.

\section{METODOLOGI PENELITIAN}

Metode pengumpulan data yang digunakan dalam penelitian ini adalah sebagai berikut : (1) Wawancara, melakukan tanya jawab secara langsung kepada pihak yang mengerti tentang objek yang akan di teliti. Seperti para pimpinan produksi dan karyawan. (2) Observasi, melakukan pengamatan langsung pada lokasi penelitian. Seperti mengamati cara kerja proses produksi dari awal sampai akhir. (3) Dokumentasi, mempelajari dokumen-dokumen perusahaan khususnya di area produksi yang bertujuan untuk mendapatkan data yang terkait dengan penelitian.

Langkah-langkah yang digunakan dalam pemecahan masalah penelitian ini adalah : (1) Dimulai dari studi literatur dan studi lapangan yaitu wawancara dan observasi (2) Kemudian dari studi tersebut dapat ditarik suatu perumusan masalah (3) Menetapkan tujuan (4) Pengumpulan data (5) Pengolahan dan analisa data dengan metode SPC, sehingga didapatkan data potensial produk cacat (6) Dan kemudian di analisa lagi menggunakan metode RCA (7) Analisa hasil (8) Rekomendasi perbaikan (9) Kesimpulan dan saran.

\section{HASIL DAN PEMBAHASAN}

Dari pengumpulan data yang berhasil dikumpulkan akan diolah dengan menggunakan metode Statistical Process Control (SPC) dan metode Root Cause Analysis. Adapun pengumpulan data tersebut dilakukan dengan cara observasi, dokumentasi, dan wawancara.

Tabel 1. Data selama observasi pada bulan februari - maret 2016 (Sumber : QC PT. XYZ).

\begin{tabular}{ccccccc}
\hline \multirow{2}{*}{ No } & Bulan & $\begin{array}{c}\text { Jumlah } \\
\text { Produksi }\end{array}$ & \multicolumn{3}{c}{ Jenis Cacat } & $\begin{array}{c}\text { Jumlah } \\
\text { Produk } \\
\text { Cacat }\end{array}$ \\
\hline \multirow{2nnnyyn}{1}{} & Februari & 702 & 136 & 30 & 214 & 380 \\
2 & Maret & 914 & 146 & 62 & 345 & 553 \\
& Total & $\mathbf{1 6 1 6}$ & $\mathbf{2 8 2}$ & $\mathbf{9 2}$ & $\mathbf{5 5 9}$ & $\mathbf{9 3 3}$ \\
\hline
\end{tabular}




\section{A. Analisa Data Statistical Process Control (SPC).}

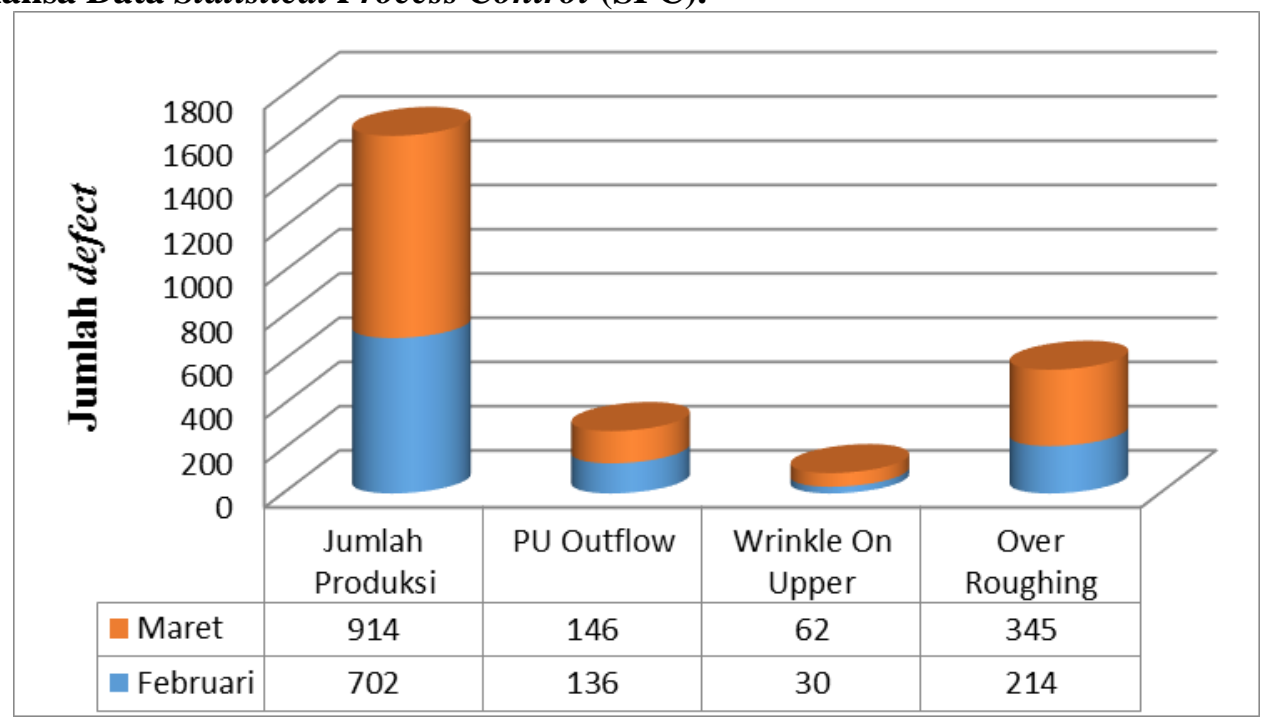

Gambar 1. Diagram batang produk cacat

Dari diagram batang tersebut maka dapat di simpulkan bahwa produk cacat (defect) yang paling potensial adalah defect Over roughing. Dan defect tersebut akan menjadi penelitian dalam tugas akhir ini untuk di analisa dan memberikan solusi untuk kedepannya agar bisa melakukan perbaikan, sehingga dapat mencegah atau mengurangi terjadinya defect Over roughing.

1. Check Sheet (Lembar periksa).

Berikut ini adalah Data Check Sheet Over roughing selama bulan februari dan maret 2016.

Tabel 2. Data Check Sheet Over Roughing (Sumber: QC PT. XYZ)

\begin{tabular}{clcc}
\hline No & Bulan & $\begin{array}{c}\text { Total } \\
\text { Produksi }\end{array}$ & $\begin{array}{c}\text { Produk cacat } \\
\text { (Defect) } \\
\text { Over Roughing }\end{array}$ \\
\hline 1 & Februari & 357 & 214 \\
2 & Maret & 489 & 345 \\
& Jumlah & $\mathbf{8 4 6}$ & $\mathbf{5 5 9}$ \\
\hline
\end{tabular}

Dari Tabel 2 diketahui bahwa total produksi selama bulan Februari dan Maret 2016 adalah sebanyak 846. Dan produk cacat (defect) Over Roughing pada bulan Februari dan Maret 2016 adalah sebanyak 559.

\section{Diagram Pareto,}

Kegunaan diagram pareto adalah untuk menentukan produk cacat (defect) yang paling banyak terjadi tiap bulan. 
Tabel 3. Data Pembuatan Diagram Pareto

\begin{tabular}{cccccc}
\hline No & Bulan & $\begin{array}{c}\text { Frekuensi } \\
\text { Produk cacat } \\
\text { (Defect) } \text { Over Roughing }\end{array}$ & $\begin{array}{c}\text { Frekuensi } \\
\text { Kumulatif }\end{array}$ & $\begin{array}{c}\text { Presentase } \\
\text { Total } \\
(\boldsymbol{\%})\end{array}$ & $\begin{array}{c}\text { Presentase } \\
\text { Kumulatif } \\
(\boldsymbol{\%})\end{array}$ \\
\hline 1 & Maret & 345 & 345 & 62 & 62 \\
2 & Februari & 214 & 559 & 38 & 100 \\
& Jumlah & $\mathbf{5 5 9}$ & & $\mathbf{1 0 0 \%}$ & \\
\hline
\end{tabular}

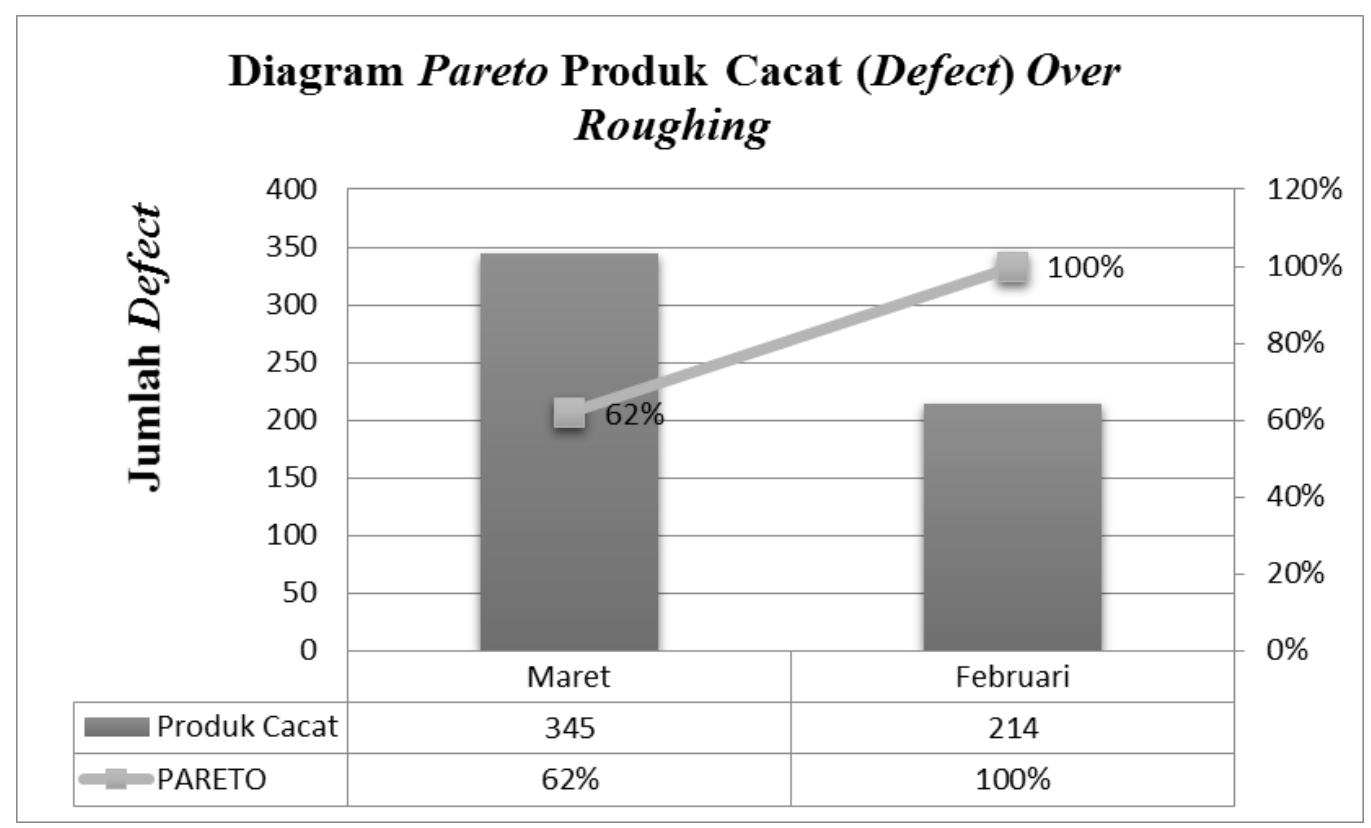

Gambar 2. Diagram Pareto Produk Cacat (Defect) Over Roughing

Pada Gambar 2 dapat diketahui bahwa frekuensi produk cacat (defect) over roughing yang paling banyak terjadi pada bulan Maret sebanyak 345 (62\%). Sedangkan frekuensi produk cacat pada bulan Februari sebanyak 214 ( 38\%). Sehingga presentase kumulatif pada diagram pareto adalah $100 \%$.

\section{Peta Kendali p (Control Chart p)}

Pembuatan peta kendali $\mathrm{p}$ (control chart $\mathrm{p}$ ) yang berfungsi untuk melihat apakah pengendalian kualitas pada PT. XYZ ini apakah sudah terkendali atau belum. pembuatan peta kendali p adalah sebagai berikut : (1) Menghitung Proporsi Produk cacat (defect). (2) Proporsi defect digunakan untuk melihat persentase defect pada tiap pengamatan proses produksi. Rumus untuk menghitung proporsi Produk cacat (defect) adalah :

$$
\mathrm{p}=\frac{\text { Jumlah produlk cacat (defect) }}{\text { Jumlah produlsi }}
$$

Berikut contoh perhitungan proporsi cacat (defect) untuk subgroup 1:

$$
\mathrm{p}=\frac{10}{13}=0,77
$$


4. Menghitung Garis Pusat Central Line (CL). (4) Garis pusat Central Line (CL) merupakan rata-rata produk cacat (defect) produk dalam suatu proses produksi. Berikut adalah perhitungan Garis Pusat Central Line (CL) dengan menggunakan rumus :

$$
\begin{aligned}
\mathrm{CL} & =\overline{\mathrm{p}}=\frac{\sum \mathrm{np} \text { (Jumlah total defect) }}{\sum \mathrm{n} \text { (Jumlah total yang di periksa) }} \\
\mathrm{CL} & =\overline{\mathrm{p}}=\frac{559}{846}=0,660
\end{aligned}
$$

5. Menghitung Batas Kendali Atas (UCL) dan Batas Kendali Bawah (LCL), Batas kendali atas (UCL) dan batas kendali bawah (LCL) merupakan indikator ukuran secara statistik sebuah proses bisa dikatakan menyimpang atau tidak. Batas kendali atas (UCL) dihitung dengan menggunakan rumus :

$$
\mathrm{UCL}=\overline{\mathrm{p}}+3 \sqrt{\frac{\overline{\mathrm{p}(1-\overline{\mathrm{p}})}}{\mathrm{n}}}
$$

Sedangkan untuk menghitung batas kendali bawah (LCL) menggunakan rumus :

$$
\mathrm{LCL}=\overline{\mathrm{p}}-3 \sqrt{\frac{\overline{\bar{p}(1-\overline{\mathrm{p}})}}{\mathrm{n}}}
$$

\begin{tabular}{|c|c|c|c|c|c|c|c|}
\hline \multirow[t]{2}{*}{ No } & \multirow{2}{*}{ Tanggal } & \multirow{2}{*}{$\begin{array}{c}\text { Total produksi } \\
(\mathrm{n}) \\
\end{array}$} & \multirow{2}{*}{$\begin{array}{c}\text { Produk cacat (defect) } \\
\text { Over Roughing(np) }\end{array}$} & \multirow[t]{2}{*}{$\mathbf{P}$} & \multirow{2}{*}{ CL } & \multirow{2}{*}{ UCL } & \multirow{2}{*}{ LCL } \\
\hline & & & & & & & \\
\hline 1 & $01 / 02 / 2016$ & 13 & 10 & 0,77 & 0,660 & 1,054 & 0,265 \\
\hline 2 & $02 / 02 / 2016$ & 15 & 9 & 0,60 & 0,660 & 1,026 & 0,293 \\
\hline 3 & $03 / 02 / 2016$ & 17 & 15 & 0,88 & 0,660 & 1,004 & 0,315 \\
\hline 4 & $04 / 02 / 2016$ & 26 & 26 & 1,00 & 0,660 & 0,938 & 0,381 \\
\hline 5 & $05 / 02 / 2016$ & 21 & 14 & 0,67 & 0,660 & 0,97 & 0,349 \\
\hline 6 & $06 / 02 / 2016$ & 19 & 9 & 0,47 & 0,660 & 0,986 & 0,333 \\
\hline 7 & $09 / 02 / 2016$ & 11 & 11 & 1,00 & 0,660 & 1,088 & 0,231 \\
\hline 8 & $10 / 02 / 2016$ & 10 & 8 & 0,80 & 0,660 & 1,109 & 0,21 \\
\hline 9 & $11 / 02 / 2016$ & 19 & 7 & 0,37 & 0,660 & 0,986 & 0,333 \\
\hline 0 & $12 / 02 / 2016$ & 15 & 11 & 0,73 & 0,660 & 1,026 & 0,293 \\
\hline 11 & $13 / 02 / 2016$ & 10 & 7 & 0,70 & 0,660 & 1,109 & 0,21 \\
\hline 12 & $15 / 02 / 2016$ & 12 & 2 & 0,17 & 0,660 & 1,07 & 0,249 \\
\hline 13 & $16 / 02 / 2016$ & 10 & 4 & 0,40 & 0,660 & 1,109 & 0,21 \\
\hline 14 & $17 / 02 / 2016$ & 20 & 8 & 0,40 & 0,660 & 0,977 & 0,342 \\
\hline 15 & $18 / 02 / 2016$ & 22 & 11 & 0,50 & 0,660 & 0,962 & 0,357 \\
\hline 16 & $19 / 02 / 2016$ & 7 & 4 & 0,57 & 0,660 & 1,197 & 0,122 \\
\hline 17 & $20 / 02 / 2016$ & 5 & 1 & 0,20 & 0,660 & 1,295 & 0,024 \\
\hline
\end{tabular}

Contoh perhitungan UCL dan LCL pada subgroup 1 :

$$
\begin{aligned}
& \mathrm{UCL}=0,660+3 \sqrt{\frac{0,660(1-0,660)}{13}}=1,054 \\
& \mathrm{LCL}=0,660-3 \sqrt{\frac{0,660(1-0,660)}{13}}=0,265
\end{aligned}
$$

Tabel 3. Hasil perhitungan Control Chart p 


\begin{tabular}{|c|c|c|c|c|c|c|c|}
\hline \multirow{2}{*}{ No } & \multirow{2}{*}{ Tanggal } & \multirow{2}{*}{$\begin{array}{c}\text { Total produksi } \\
(\mathbf{n}) \\
\end{array}$} & \multirow{2}{*}{$\begin{array}{c}\text { Produk cacat }(\text { defect }) \\
\text { Over Roughing(np) }\end{array}$} & \multirow{2}{*}{$\mathbf{P}$} & \multirow{2}{*}{ CL } & \multirow{2}{*}{ UCL } & \multirow{2}{*}{ LCL } \\
\hline & & & & & & & \\
\hline 18 & $22 / 02 / 2016$ & 13 & 4 & 0,31 & 0,660 & 1,054 & 0,265 \\
\hline 19 & $23 / 02 / 2016$ & 17 & 4 & 0,24 & 0,660 & 1,004 & 0,315 \\
\hline 20 & $24 / 02 / 2016$ & 24 & 20 & 0,83 & 0,660 & 0,95 & 0,369 \\
\hline 21 & $25 / 02 / 2016$ & 15 & 11 & 0,73 & 0,660 & 1,026 & 0,293 \\
\hline 22 & $26 / 02 / 2016$ & 16 & 6 & 0,38 & 0,660 & 1,015 & 0,304 \\
\hline 23 & $27 / 02 / 2016$ & 12 & 4 & 0,33 & 0,660 & 1,07 & 0,249 \\
\hline 24 & $29 / 02 / 2016$ & 8 & 8 & 1,00 & 0,660 & 1,162 & 0,157 \\
\hline 25 & 01/03/2016 & 12 & 9 & 0,75 & 0,660 & 1,07 & 0,249 \\
\hline 26 & $02 / 03 / 2016$ & 20 & 13 & 0,65 & 0,660 & 0,977 & 0,342 \\
\hline 27 & 03/03/2016 & 8 & 5 & 0,63 & 0,660 & 1,162 & 0,157 \\
\hline 28 & $04 / 03 / 2016$ & 20 & 10 & 0,50 & 0,660 & 0,977 & 0,342 \\
\hline 29 & 05/03/2016 & 17 & 12 & 0,71 & 0,660 & 1,004 & 0,315 \\
\hline 30 & 07/03/2016 & 22 & 14 & 0,64 & 0,660 & 0,962 & 0,357 \\
\hline 31 & 08/03/2016 & 6 & 6 & 1,00 & 0,660 & 1,24 & 0,079 \\
\hline 32 & $10 / 03 / 2016$ & 7 & 7 & 1,00 & 0,660 & 1,197 & 0,122 \\
\hline 33 & $11 / 03 / 2016$ & 10 & 10 & 1,00 & 0,660 & 1,109 & 0,21 \\
\hline 34 & $12 / 03 / 2016$ & 17 & 12 & 0,71 & 0,660 & 1,004 & 0,315 \\
\hline 35 & $14 / 03 / 2016$ & 26 & 17 & 0,65 & 0,660 & 0,938 & 0,381 \\
\hline 36 & $15 / 03 / 2016$ & 19 & 9 & 0,47 & 0,660 & 0,986 & 0,333 \\
\hline 37 & $16 / 03 / 2016$ & 13 & 9 & 0,69 & 0,660 & 1,054 & 0,265 \\
\hline 38 & $17 / 03 / 2016$ & 9 & 9 & 1,00 & 0,660 & 1,133 & 0,186 \\
\hline 39 & $18 / 03 / 2016$ & 16 & 14 & 0,88 & 0,660 & 1,015 & 0,304 \\
\hline 40 & $19 / 03 / 2016$ & 20 & 10 & 0,50 & 0,660 & 0,977 & 0,342 \\
\hline 41 & $21 / 03 / 2016$ & 17 & 6 & 0,35 & 0,660 & 1,004 & 0,315 \\
\hline 42 & $22 / 03 / 2016$ & 20 & 13 & 0,65 & 0,660 & 0,977 & 0,342 \\
\hline 43 & $23 / 03 / 2016$ & 30 & 27 & 0,90 & 0,660 & 0,919 & 0,4 \\
\hline 44 & $24 / 03 / 2016$ & 43 & 30 & 0,70 & 0,660 & 0,876 & 0,443 \\
\hline 45 & $25 / 03 / 2016$ & 4 & 2 & 0,50 & 0,660 & 1,37 & $-0,05$ \\
\hline 46 & $26 / 03 / 2016$ & 33 & 23 & 0,70 & 0,660 & 0,907 & 0,412 \\
\hline 47 & $28 / 03 / 2016$ & 32 & 31 & 0,97 & 0,660 & 0,911 & 0,408 \\
\hline 48 & $29 / 03 / 2016$ & 29 & 20 & 0,69 & 0,660 & 0,923 & 0,396 \\
\hline 49 & $30 / 03 / 2016$ & 19 & 11 & 0,58 & 0,660 & 0,986 & 0,333 \\
\hline 50 & $31 / 03 / 2016$ & 20 & 16 & 0,80 & 0,660 & 0,977 & 0,342 \\
\hline
\end{tabular}




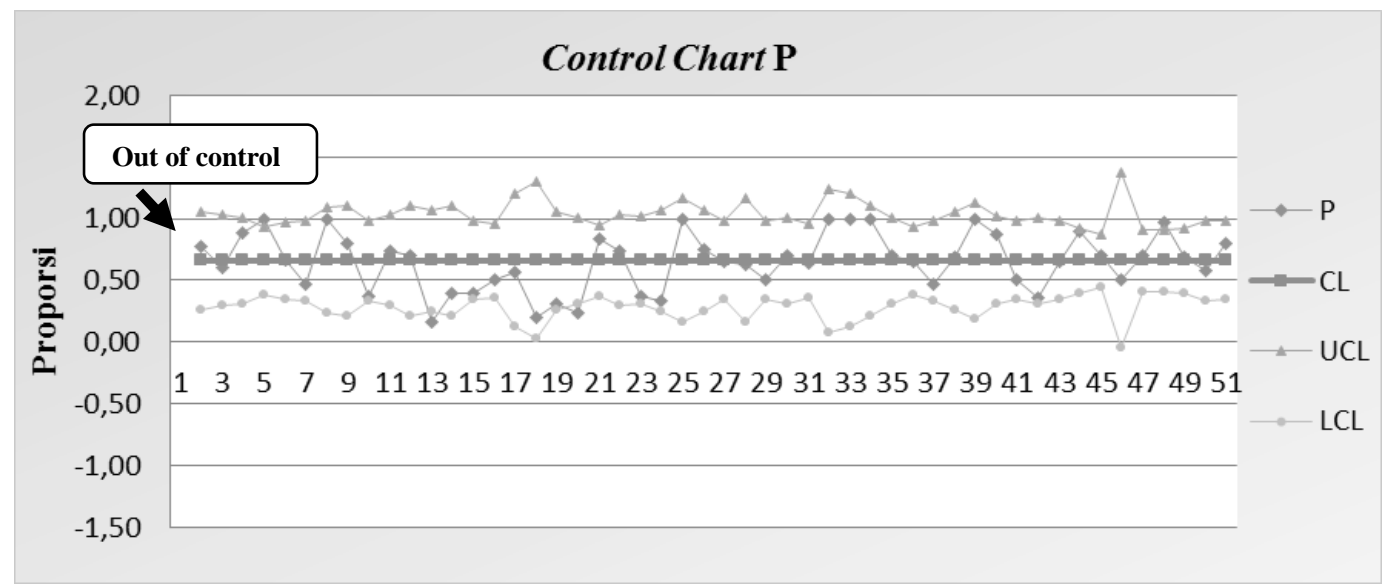

Gambar 3. Control Chart p Defect Over Roughing

Berdasarkan Gambar 3 dapat disimpulkan bahwa data-data tersebut dalam keadaan tidak terkendali. Karena dari ke-50 data tersebut terdapat satu titik data yang berada di luar batas kontrol (out of control), yaitu pada titik ke- 4 Data tersebut mempunyai nilai proporsi sebesar 1, diluar batas Upper Control Limit (UCL) yaitu sebesar 0,938.

6. Membuat Diagram Sebab-Akibat, kemudian tahap berikutnya adalah mencari akar permasalahan yang menyebabkan produk cacat (defect) over roughing sepatu dan selanjutnya dianalisa faktor-faktor yang dapat menyebabkan produk sepatu tersebut yang mengalami cacat $($ defect).

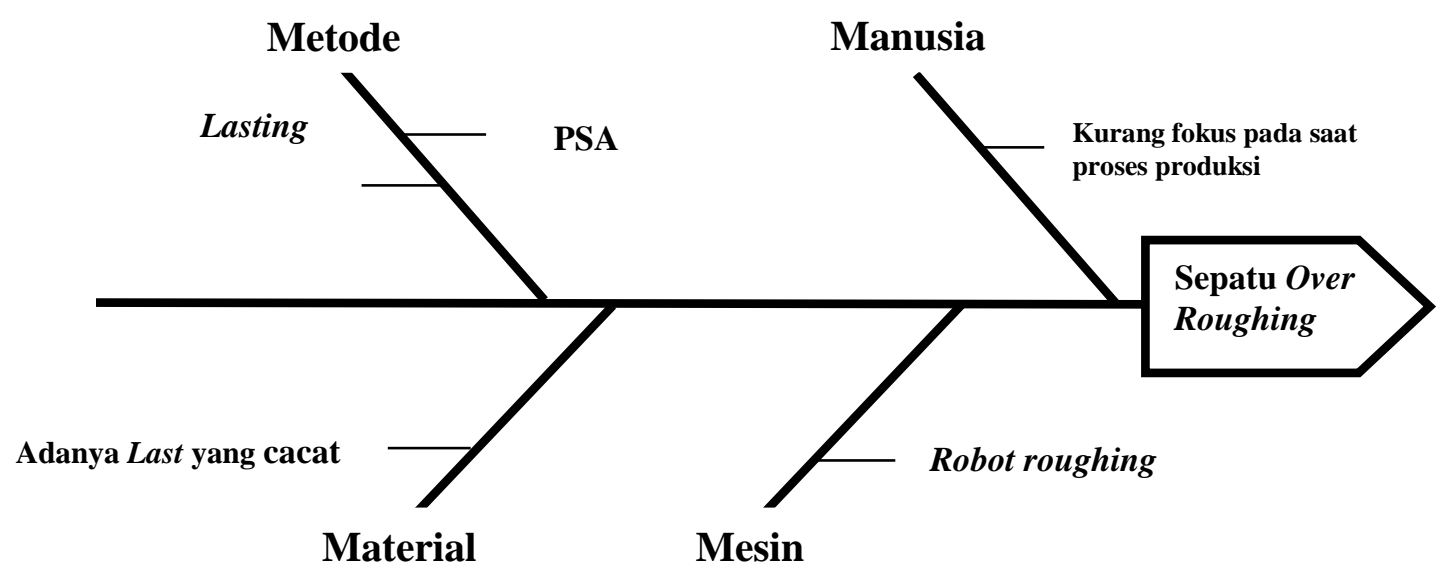

Gambar 4. Diagram Sebab-Akibat Produk Cacat (Defect) Over Roughing

Berdasarkan Gambar tersebut diketahui faktor-faktor yang menyebabkan adanya Produk Cacat (Defect) Over Roughing antara lain : (1) faktor manusia, (2) faktor metode, (3) faktor mesin, (4) faktor material. 


\section{B. Analisa Data Root Cause Analysis (RCA)}

Gambar berikut adalah Root Cause Analysis (RCA) untuk defect Over Roughing.

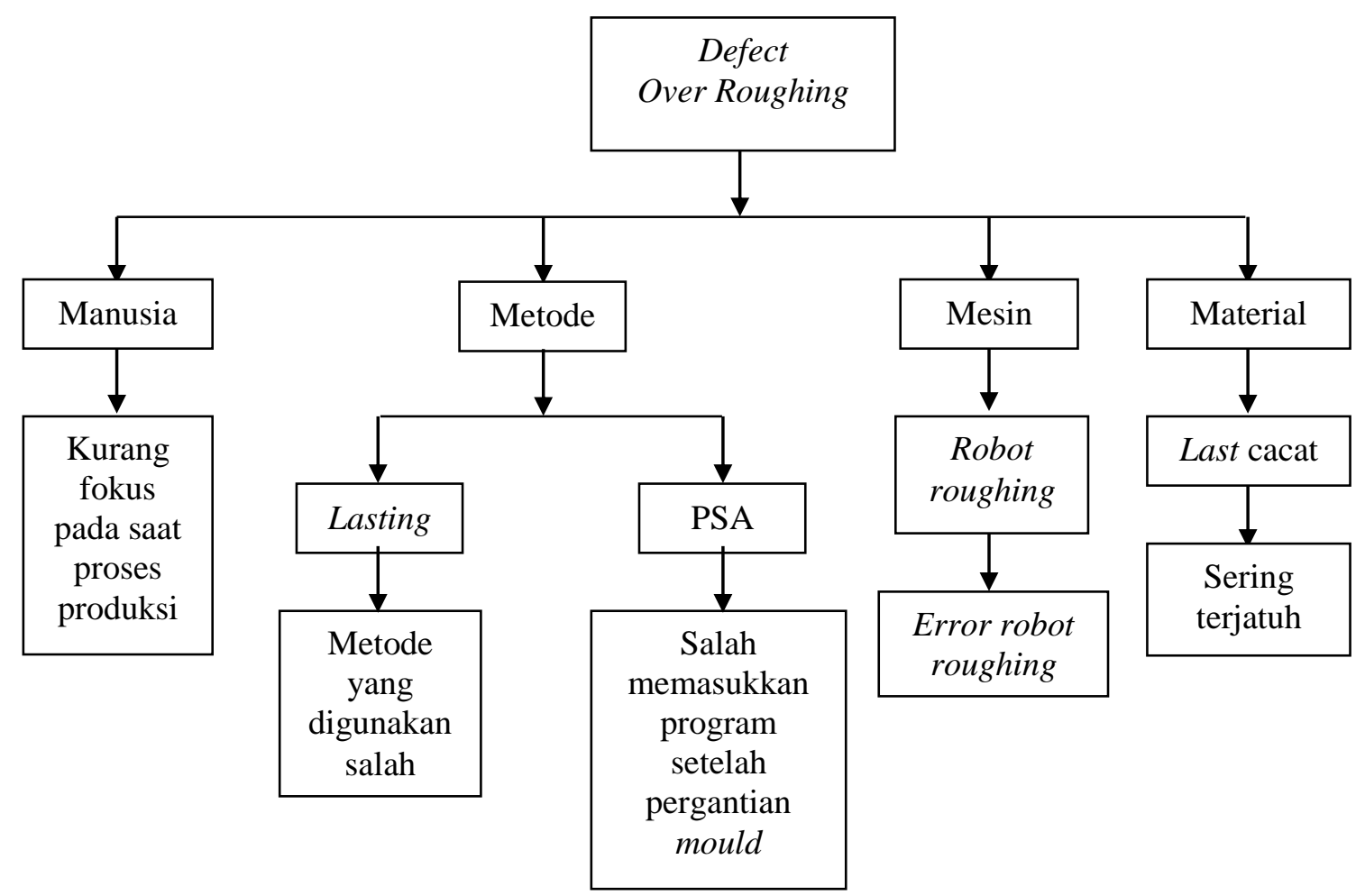

Gambar 5. Root Cause Analysis (RCA) Defect Over Roughing

\section{Analisa menggunakan 5 Why Method}

Dari pengumpulan data yang dilakukan, diketahui terdapat empat faktor utama penyebab terjadinya potensi kegagalan yang terlihat pada Tabel berikut

Tabel 4. Faktor penyebab proses kritis

\begin{tabular}{cc}
\hline Faktor & Nama Faktor \\
\hline A & Manusia \\
B & Mesin \\
C & Metode \\
D & Material \\
\hline
\end{tabular}

Tabel 5. Root Cause Analysis (RCA) 5 Why Method (Manusia)

\begin{tabular}{|c|c|c|c|c|c|c|}
\hline Defect & Why 1 & Why 2 & Why 3 & Why 4 & Why 5 & Faktor \\
\hline $\begin{array}{l}\text { Over } \\
\text { Roughing }\end{array}$ & Manusia & $\begin{array}{l}\text { Kurang } \\
\text { fokus } \\
\text { pada saat } \\
\text { proses } \\
\text { produksi }\end{array}$ & $\begin{array}{l}\text { Kesulitan } \\
\text { pada } \\
\text { pemasangan } \\
\text { artikel }\end{array}$ & $\begin{array}{l}\text { Banyaknya } \\
\text { jumlah } \\
\text { order } \\
\text { (dikejar } \\
\text { target) }\end{array}$ & $\begin{array}{l}\text { Karyawan } \\
\text { terburu- } \\
\text { buru }\end{array}$ & $\mathrm{A}, \mathrm{D}$ \\
\hline
\end{tabular}

Dari analisa tabel 5 tersebut di dapatkan hasil untuk faktor yang menyebabkan terjadinya defect over roughing sepatu adalah dari faktor manusia, karena kurang fokus dalam proses produksi dan kecapean akibat dari artikel yang sulit serta ditambahkan lagi dengan banyaknya jumlah order (dikejar target), ahirnya karyawan terburu buru pada saat 
mengerjakan proses produksi sehingga menyebabkan kualitas dari proses produksi kurang optimal. Dan faktor penyebab proses kritis adalah manusia dan material.

Tabel 6. Root Cause Analysis (RCA) 5 Why Method (Metode)

\begin{tabular}{|c|c|c|c|c|c|c|}
\hline Defect & Why 1 & Why 2 & Why 3 & Why 4 & Why 5 & Faktor \\
\hline $\begin{array}{l}\text { Over } \\
\text { Roughing }\end{array}$ & $\begin{array}{l}\text { Metode yang } \\
\text { digunakan salah } \\
\text { Salah } \\
\text { memasukkan } \\
\text { program setelah } \\
\text { pergantian mould }\end{array}$ & $\begin{array}{l}\text { Tidak ada } \\
\text { konfirmasi } \\
\text { dalam } \\
\text { team work }\end{array}$ & $\begin{array}{l}\text { Kesalahan } \\
\text { teknis dalam } \\
\text { melakukan } \\
\text { proses } \\
\text { produksi }\end{array}$ & $\begin{array}{l}\text { Belum } \\
\text { adanya } \\
\text { sosialisasi } \\
\text { tentang } \\
\text { produk }\end{array}$ & $\begin{array}{l}\text { Kurang } \\
\text { teliti } \\
\text { karyawan } \\
\text { pada saat } \\
\text { proses } \\
\text { produksi }\end{array}$ & $\mathrm{A}, \mathrm{B}, \mathrm{C}$ \\
\hline
\end{tabular}

Kemudian dari analisa tabel 6 tersebut hasil yang didapatkan untuk faktor yang menyebabkan terjadinya defect over roughing sepatu adalah dari faktor metode, karena dari proses lasting metode yang digunakn salah dan dari proses PSA salah memasukkan program setelah pergantian mould. Kemudian di analisa lagi disebabkan karena tidak ada konfirmasi dalam tim kerja dan kesalahan teknis dalam melakukan proses produksi, ditambah lagi dengan belum adanya sosialisasi tentang produk serta kurang teliti karyawan pada saat proses produksi. Dan faktor penyebab proses kritis untuk defect over roughing dilihat dari faktor metode adalah manusia, mesin dan metode.

Tabel 7. Root Cause Analysis (RCA) 5 Why Method (Mesin)

\begin{tabular}{lllllll}
\hline Defect & Why $\mathbf{1}$ & Why 2 & Why $\mathbf{3}$ & Why $\mathbf{4}$ & Why 5 & Faktor \\
\hline $\begin{array}{l}\text { Over } \\
\text { Roughing }\end{array}$ & $\begin{array}{l}\text { Error } \\
\text { robot } \\
\text { roughing }\end{array}$ & $\begin{array}{l}\text { Stop mesin/ } \\
\text { Emergency }\end{array}$ & $\begin{array}{l}\text { Problem } \\
\text { kualitas }\end{array}$ & $\begin{array}{l}\text { Belum } \\
\text { dilakukan } \\
\text { penyesuaian } \\
\text { roughing }\end{array}$ & $\begin{array}{l}\text { Belum adanya } \\
\text { pembaruan } \\
\text { standar mesin }\end{array}$ & A,B \\
& & & & & \\
\hline
\end{tabular}

Berdasarkan analisa tabel 7 tersebut untuk penyebab defect over roughing sepatu dilihat dari faktor mesin adalah terjadinya error robot roughing yang disebabkan stop mesin secara tiba-tiba atau emergency yang di tekan oleh orang Quality Control (QC) karena masalah kualitas. Kemudian di analisa lagi disebabkan belum dilakukan penyesuaian roughing terhadap robot roughing dan di sinyalir karena belum adanya pembaruan standar mesin yang menyebabkan defect over roughing terjadi. Dan faktor penyebab proses kritisnya adalah manusia dan mesin.

Tabel 8. Root Cause Analysis (RCA) 5 Why Method (Material)

\begin{tabular}{lllllll}
\hline Defect & Why $\mathbf{1}$ & Why 2 & Why 3 & Why 4 & Why 5 & Faktor \\
\hline $\begin{array}{l}\text { Over } \\
\text { Roughing }\end{array}$ & $\begin{array}{l}\text { Last } \\
\text { cacat }\end{array}$ & $\begin{array}{l}\text { Sering } \\
\text { terjatuh }\end{array}$ & $\begin{array}{l}\text { Produk tidak } \\
\text { ditempatkan } \\
\text { dengan } \\
\text { benar }\end{array}$ & $\begin{array}{l}\text { Terdapat } \\
\text { kemiripan } \\
\text { bentuk material }\end{array}$ & $\begin{array}{l}\text { Karyawan kurang } \\
\text { teliti dan fokus } \\
\text { dalam produksi }\end{array}$ & A,B,D \\
\end{tabular}

Sedangkan analisa dari tabel 8 tersebut didapatkan hasil untuk penyebab defect over roughing dilihat dari faktor material adalah disebabkan oleh adanya last cacat akibat dari sering terjatuh baik ditimbulkan oleh manusia atau mesin karena produk tidak ditempatkan dengan benar. Kemudian di analisa lagi karena terdapat kemiripan bentuk material dan 
karyawan kurang teliti dan fokus dalam proses produksi. Dan faktor penyebab proses kritisnya adalah manusia, mesin dan material.

\section{Rekomendasi perbaikan}

Rekomendasi perbaikan yang dapat diberikan untuk permasalahan ini adalah dengan cara : (1) Faktor Manusia. (a) Merevisi kembali WI (Work Instruction) instruksi kerja. Dengan adanya WI (Instruksi kerja), maka dapat membantu karyawan dalam proses produksi, karena didalamnya terdapat alur yang teratur untuk beroperasi dalam bekerja. (b) Memberikan sosialisasi dan pelatihan tentang produk untuk karyawan. Sosialisasi tentang produk diberikan ketika produk tersebut akan dijalankan pada proses produksi, sehingga karyawan dapat mengetahui poin-poin penting dari produk tersebut. Dan mengadakan pelatihan untuk karyawan dengan materi metode proses produksi terbaru (teknik terbaru) untuk suatu produk baru. Implementasi dilakukan untuk karyawan lama dan karyawan baru minimal satu tahun sekali. (c) Penghargaan. Penghargaan diberikan kepada karyawan jika hasil yang dicapai sangat memuaskan dan menguntungkan bagi perusahaan. (2) Faktor mesin . Rekomendasi perbaikan yang harus dilakukan adalah dengan cara melakukan inspeksi peralatan dan mesin atau sarana penunjang lainnya apakah sudah benar-benar dalam kondisi standar, sehingga mesin tersebut dapat bekerja sebagaimana dengan standar yang sudah ditetapkan oleh perusahaan. (3) Faktor Metode. Memberikan informasi tentang metode dan program tentang mesin bagi karyawan, karena apabila ada kesalahan tentang metode dan program tersebut, maka hasilnya adalah tidak bagus dan hal tersebut sangat merugikan perusahaan. (4) Faktor Material. Rekomendasi yang disarankan untuk faktor material adalah tentang last pada proses lasting, biasanya ditemukan last tidak sama bentuknya dalam satu pasang. Yang harus dilakukan adalah perbaikan sistem penyimpanan pada gudang penyimpanan, menata kembali tempat penyimpanan material serta bagian gudang menyiapkan satu paket bahan baku sesuai dengan komponen yang di produksi, agar dalam pengambilannya dapat memudahkan karyawan.

\section{KESIMPULAN DAN SARAN}

\section{A. Kesimpulan}

Pada Analisa check sheet dan diagram pareto dapat diketahui frekuensi produk cacat (defect) over roughing yang paling banyak terjadi pada bulan Maret 2016 sebanyak 345 sepatu (62\%) dari total produksi 489 produk. Kemudian frekuensi kedua pada bulan Februari 2016 sebanyak 214 sepatu (38\%) dari total produksi 357 produk. Dan dari gambar Control Chart P dapat disimpulkan bahwa data-data tersebut dalam keadaan tidak terkendali. Karena dari ke-50 data tersebut terdapat satu titik data yang berada di luar batas kontrol (out of control), yaitu pada titik ke- 4 Data tersebut mempunyai nilai proporsi sebesar 1, diluar batas Upper Control Limit (UCL) yaitu sebesar 0,938. Selama titik-titik terletak di dalam batas-batas pengendali, proses dianggap dalam keadaan terkendali, dan tidak perlu tindakan apapun. Tetapi, satu titik yang terletak di luar batas pengendali diinterpretasikan sebagai fakta bahwa pengendalian kualitas pada proses produksi (injection) PT. XYZ tidak terkendali atau masih mengalami penyimpangan. Faktor penyebab proses kritis yang mempengaruhi kegagalan pada proses produksi adalah manusia, mesin, metode dan material. Dari identifikasi perbaikan proses produksi didapatkan rekomendasi sebagai berikut: (a). Merevisi kembali WI (instruksi kerja), sosialisasi dan pelatihan, serta penghargaan untuk karyawan. (b). Dilakukan inspeksi peralatan dan sarana penunjang lainnya. (c). Diperlukan informasi metode dan program mesin tentang produk untuk karyawan. (d). Perbaikan sistem penyimpanan dan penataan last yang sesuai dengan kebutuhan proses produksi.

\section{B. Saran}

Penelitian untuk peningkatan kualitas produk sepatu di PT. XYZ sebaiknya dilakukan secara berkala. Dan untuk penelitian selanjutnya dapat dibuat penelitian hingga kontrol sehingga hasil dari usulan perbaikan dapat dibuktikan tingkat keberhasilannya. 


\section{DAFTAR PUSTAKA}

[1] Alwi (2011). Root Cause Analysis Pada Kebakaran KMP. Nusa bhakti, Jurnal Teknik Perkapalan Volume 5 Universitas Hasanuddin-Makasar 2011.

[2] Gaspersz,V.1998. Statistical Process Control Manajemen Bisnis Total. PT.Gramedia Pustaka Utama, Jakarta.

[3] Gaspersz,V.2003. Metode Analisis Untuk Peningkatan Kualitas. PT.Gramedia Pustaka Utama, Jakarta.

[4] Handoko (2013). Penerapan Integrasi Metode Statistical Process Control Dan Taguchi Untuk Mengoptimalkan Kadar Tanin Teh Cair Pahit Pada Proses Penyeduhan Teh (Studi Kasus di PT.Sinar Sosro-KPB Mojokerto), Fakultas Teknik Universitas Muhammadiyah Sidoarjo 2013.

[5] (Himawan (2013). Pengendalian kualitas Statistical Process Control (SPC) Produk Genteng di UKM Super Soka Jepara, Fakultas Teknik Universitas Dian Nuswantoro Semarang 2013.

[6] Ilham (2012). Analisis Pengendalian Kualitas Produk dengan Menggunakan Statistical Process Control (SPC) pada PT. BOSOWA MEDIA GRAFIKA (TRIBUN TIMUR), Skripsi Jurusan Manejemen, Universitas Hasanuddin 2012.

[7] Kaban (2014). Pengendalian Kualiatas Kemasan Plastik Pouch Menggunakan Statistical Process Control (SPC), Studi Kasus PT. INCASI RAYA PADANG, Jurnal Optimasi Sistem Industri, Vol. 13 N0. 1, April 2014.

[8] Lindawati dkk (2013). Perancangan Proses Produksi Alat Antrian C2000 Dengan Menggunakan IDEFO, FMEA Dan Root Cause Analysis (RCA), Jurnal Rekayasa Dan Manejemen Sistem Industri Vol.3 No.2 Teknik Industri Universitas Brawijaya 2013.

[9] Lindsay, Evans (2007). Pengantar Six Sigma, Salemba Empat, Wijaya Grand Center Blok D-7, Jl. Wijaya 2, Jakarta 12160.

[10] Masaaki Imai (2001). Kaizen, Kunci sukses Jepang dalam persaingan, Mariani Grandamihardja, Jakarta: PPM, 2001.

[11] Montgomery (1993). Pengantar Pengendalian Kualitas Statistik, Indonesia, Gajah Mada University Press, P.O. Box 14, Bulaksumur, Yogyakarta, Indonesia.

[12]Zoraya (2012). Perbaikan Proses Bisnis Pelayanan Penanganan Gangguan Melalui Pendekatan IDEFO-FMEA Dan Root Cause Analysis, Jurnal Teknik Industri (ITS) Teknik Pomits Vol. 1, No.1, (2012)1-5. 